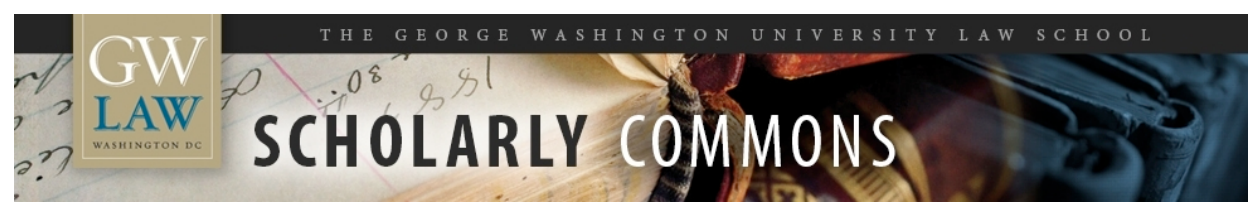

GW Law Faculty Publications \& Other Works

Faculty Scholarship

2017

\title{
Awareness as a First Step Toward Overcoming Implicit Bias
}

Cynthia Lee

George Washington University Law School, cylee@law.gwu.edu

Follow this and additional works at: https://scholarship.law.gwu.edu/faculty_publications

Part of the Law Commons

\section{Recommended Citation}

Lee, Cynthia, Awareness as a First Step Toward Overcoming Implicit Bias (2017). Enhancing Justice: Reducing Bias 289 (Sarah Redfiled et al. eds., 2017); GWU Law School Public Law Research Paper No. 2017-56; GWU Legal Studies Research Paper No. 2017-56. Available at SSRN: http://ssrn.com/ abstract $=3011381$

This Chapter is brought to you for free and open access by the Faculty Scholarship at Scholarly Commons. It has been accepted for inclusion in GW Law Faculty Publications \& Other Works by an authorized administrator of Scholarly Commons. For more information, please contact spagel@law.gwu.edu. 


\title{
Chapter 11
}

\section{Awareness as a First Step Toward Overcoming Implicit Bias}

\author{
Cynthia Lee
}

\section{Chapter Contents}

Introduction

I. Raising Awareness
A. Implicit Bias Trainings and Efforts to Educate Jurors about Implicit Bias
B. Making Race (or Other Types of Bias) Salient
C. Awareness Alone Is Not Sufficient to Break the Prejudice Habit Conclusion

\section{Chapter Highlights}

- Awareness is a necessary first step toward reducing implicit bias.

- One way to raise awareness about racial bias in a criminal case is to make race salient.

- Making race salient means calling attention to the possibility that racial stereotypes or racial prejudice may have influenced the actions of the parties in the case.

- Becoming aware of the existence of implicit bias and the fact that everyone is influenced by implicit bias alone is not sufficient to break the prejudice habit.

- One must also be motivated to break the prejudice habit and be trained in ways to overcome bias. 


\section{Introduction}

For more than half a century, research on bias has focused on the idea that interpersonal contact with diverse others is the best way to reduce prejudice. Perhaps the most well-known proponent of the intergroup contact thesis was Gordon Allport, who argued in his book, The Nature of Prejudice, that intergroup interactions involving individuals of equal status from different groups would lead to a reduction in prejudice. ${ }^{1}$ Since Allport's book was first published in 1954, much of the empirical research on bias reduction has focused on Allport's intergroup contact hypothesis. ${ }^{2}$ This research has confirmed that intergroup contact reduces self-reported measures of prejudice. ${ }^{3}$

Allport's work relied on conscious action and self-reporting. Self-reporting, however, tells only half the story. One can honestly believe it is wrong to discriminate against others and thus have low self-reported measures of prejudice, yet still have biased thoughts and engage in discriminatory behavior. A wealth of research over the past decade has shown that even when individuals do not consciously embrace prejudicial attitudes, they still manifest implicit bias, reflected in the tendency to associate members of different social groupsAfrican-Americans, Latinos, Asian-Americans, gays, elderly people, and women-with stereotypes of these groups. This kind of stereotyping often takes place without conscious thought or awareness.

The existence of implicit bias has been demonstrated by several different measures, including the Implicit Association Test (IAT), which compares response times when individuals are tasked with linking different sets of images and words. ${ }^{4}$ The IAT measures implicit bias by comparing the amount of time it takes to hit a specified computer key when one is shown images and words that one expects to go together, such as images of flowers and positive words like "pretty," to response times when one observes images and words that one does not expect to go together, such as pictures of cockroaches and words like "lovely." ${ }^{1}$ Time after time, individuals respond more quickly when they see images and words that are typically associated with one another and more slowly when they see images and words that are not commonly linked. ${ }^{6}$ For example, most people are quicker to link Black faces with negative words and White faces with positive words, suggesting implicit racial bias in favor of Whites and against Blacks. ${ }^{7}$ Most people, including the elderly themselves, are quicker to associate good words with young people and bad words with elderly people, suggesting implicit ageism. ${ }^{8}$ Over 14 million IATs measuring bias based on age, gender, ethnicity, and other kinds of biases have been recorded. ${ }^{9}$ Seventy-five percent of the individuals who have taken the race IAT have demonstrated implicit bias in favor of Whites over Blacks. ${ }^{10}$

Once social scientists began to recognize that bias can operate without conscious awareness, they began trying to find ways to reduce not simply outward expressions of prejudice but also implicit bias. Reducing implicit bias, however, has proven to be a more difficult task than reducing explicit expressions 
of prejudice. This is because all of us engage in what Patricia Devine calls the prejudice habit. ${ }^{11}$ Devine posits that in order to break the prejudice habit, there must be (1) awareness, (2) desire or motivation to break the prejudice habit, ${ }^{12}$ and (3) training in ways that one can overcome bias. ${ }^{13}$

\section{Raising Awareness}

This chapter focuses on just the first step in breaking the prejudice habit: making people aware of implicit bias. While some social scientists have questioned whether making people aware of implicit bias can actually reduce bias, ${ }^{14}$ social psychologists and others who study racial bias generally agree that awareness of the existence of implicit bias is an important first step towards reducing bias. ${ }^{15}$

\section{A. Implicit Bias Trainings and Efforts to Educate Jurors about Implicit Bias}

One way to raise awareness about implicit bias is to simply inform individuals about its existence. Lectures and workshops on implicit bias have become more commonplace in various institutional settings, including in workplaces, ${ }^{16}$ law schools, ${ }^{17}$ law enforcement agencies, ${ }^{18}$ and other enterprises. For example, ${ }^{1}[\mathrm{~m}]$ ore than half of Google's nearly 56,000 employees have attended a 90-minute seminar on unconscious bias," and nearly 2,000 of Google's employees have attended "bias busting" workshops that "give Google employees practical tips on addressing unconscious bias." ${ }^{19}$ In response to accusations of racial bias by hosts renting their homes through Airbnb, Airbnb

[1]n order to break the prejudice habit, there must be (1) awareness, (2) desire or motivation to break the prejudice habit, and (3) training in ways that one can overcome bias.

-Patricia Devine announced in September 2016 that it would offer implicit bias training to its hosts. ${ }^{20}$ In the government sector, on June 27, 2016, the Department of Justice announced that it would require its 23,000 law enforcement agents and 5,800 lawyers in U.S. Attorney's offices across the nation to engage in implicit bias training aimed at getting them to recognize and address implicit bias in their workplace decisions. ${ }^{21}$

Attention to implicit bias training is also present in courtroom settings, where some judges have started informing jurors about the existence of implicit bias and the need to try to guard against such bias. For example, the Honorable Mark Bennett, ${ }^{22}$ a federal district court judge in Iowa, routinely tells his jurors,

Do not decide the case based on "implicit biases." As we discussed in jury selection, everyone, including me, has feelings, assumptions, perceptions, fears, and stereotypes, that is, "implicit biases," that we may not be aware of. These hidden thoughts can impact what we 
see and hear, how we remember what we see and hear, and how we make important decisions. Because you are making very important decisions in this case, I strongly encourage you to evaluate the evidence carefully and to resist jumping to conclusions based on personal likes or dislikes, generalizations, gut feelings, prejudices, sympathies, stereotypes, or biases. The law demands that you return a just verdict, based solely on the evidence, your individual evaluation of that evidence, your reason and common sense, and these instructions. Our system of justice is counting on you to render a fair decision based on the evidence, not on biases. ${ }^{23}$

Attorneys are also educating jurors about implicit bias. ${ }^{24}$ For example, in one criminal case out of Alaska, defense attorneys representing a Black teenager charged with assaulting a White ${ }^{25}$ classmate were worried that their all-White jury would assume their client was guilty because of racial stereotypes linking Blacks with violence and criminality. ${ }^{26}$ To combat this potential bias, the attorneys spoke about their own racial biases during voir dire to let potential jurors know that it is normal to have racial bias. ${ }^{27}$ They also successfully requested that the judge give the jurors a race-switching jury instruction based on a model jury instruction I first proposed in a law review article. ${ }^{28}$ Essentially, the raceswitching jury instruction told jurors they should think about the case with the same facts except imagine that the defendant was a White teenage boy and the victim was his Black classmate before deciding whether to find the defendant guilty or not guilty. ${ }^{29}$ The jury found the defendant not guilty. Switching as a means of raising awareness about bias can work in other contexts besides race. ${ }^{30}$

Limited research has been done on the effectiveness of implicit bias trainings in general and efforts to educate jurors about implicit bias in particular. The available research, however, suggests that implicit bias training that simply informs or educates individuals about the existence of implicit bias is insufficient. To have any lasting impact, such trainings must give individuals strategies for reducing bias. ${ }^{31}$ Similarly, making jurors aware of the existence of implicit bias and the fact that it may affect their own decision making may not be sufficient to make a difference in outcomes. ${ }^{32}$ One study, for example, found that jury instructions informing jurors about the existence of implicit bias and instructing jurors to try to resist relying on generalizations and stereotypes had no significant effect on judgments of guilt, belief in the strength of the prosecution's evidence, or length of sentence. ${ }^{33}$

\section{B. Making Race (or Other Types of Bias) Salient}

Another way to raise awareness about implicit racial bias in the context of a criminal case is to make the possibility of such bias salient. A wealth of recent research on race salience demonstrates that calling attention to the possibility of racial bias in others can encourage jurors to treat Black and White defendants the same way. Samuel Sommers and Phoebe Ellsworth have conducted 
numerous experiments studying the possibility that if racial prejudice is made salient to mock jurors in a criminal case, those jurors are more likely to treat similarly situated Black and White defendants the same way.

In one experiment, for example, 196 White individuals were approached by a White experimenter in waiting areas of a major international airport and asked if they would read a written trial summary and complete a questionnaire about legal attitudes while they waited. ${ }^{34}$ The trial summary described a case involving a high school basketball player who had an altercation with a fellow teammate in the locker room, resulting in a charge of battery with serious bodily injury. ${ }^{35}$ Half the mock jurors were given a trial summary with a White defendant and a Black victim, while half were given the same trial summary with a Black defendant and a White victim. In both the race-salient and non-race-salient conditions, participants were given a description of the defendant and victim, which included the height, weight, race, gender, and age of each. ${ }^{36}$ In some of the trial summaries, race was made salient through the testimony of a defense witness who "testified that the defendant was one of the only two Whites (or Blacks) on the team, and had been the 'subject of racial remarks and unfair criticism throughout the season from many of his Black (or White) teammates." ${ }^{\prime 37}$ In others, race was not made salient. ${ }^{38}$ In the non-racesalient version of the case, there was no mention of the defendant's race nor any mention of racial remarks. ${ }^{39}$ Instead, the defense witness testified that "the defendant had only one other friend on the team and had been the 'subject of obscene remarks and unfair criticism from many of his teammates." 40 Other than this testimony, the written trial summaries were the same. ${ }^{41}$

Sommers and Ellsworth found that the White mock jurors were significantly more likely to convict the Black defendant in the non-race-salient condition (90 percent) than in the race-salient condition (70 percent) ${ }^{42}$ When race was made salient, conviction rates for the White defendant (69 percent) and the Black defendant (66 percent) were fairly comparable. ${ }^{43}$ When participants were asked to rate the strength of the prosecution's case, they rated the prosecution's case against the Black defendant as significantly stronger in the non-race-salient condition than the exact same prosecution case against the Black defendant in the race-salient condition. ${ }^{44}$ Participants were also asked to recommend a sentence for the defendant. ${ }^{45}$ In the non-race-salient condition, mock jurors recommended a more severe sentence for the Black defendant than the White defendant than in the race-salient condition. ${ }^{46}$ Sommers and Ellsworth concluded that when race was made salient, the participants did not demonstrate prejudice "because the racial content of the trial activated a motivation to appear non-prejudiced." 47 On the other hand, "when race was not a salient issue, a motivation to avoid prejudice was not expected among jurors, and White mock jurors did indeed demonstrate racial bias in their judgments." 48

In another study, Sommers and Ellsworth had 211 individuals who were waiting to depart from gates at a large international airport read a trial 
summary about a man charged with assault and battery against his girlfriend. ${ }^{49}$ The man was at a bar with his coworkers celebrating a recent promotion when his girlfriend stood up and started making fun of his physique and sexual performance. ${ }^{50}$ The defendant yelled at his girlfriend, forced her into a chair, and then slapped her. ${ }^{51}$ The slap knocked the girlfriend to the ground, injuring her ankle. ${ }^{52}$ In the race-salient version of the case, the girlfriend testifies that the defendant yelled, "You know better than to talk that way about a White (or Black) man in front of his friends. ${ }^{153}$ In the non-race-salient version, she testifies that the defendant yelled, "You know better than to talk that way about a man in front of his friends." ${ }^{54}$ The only difference between the race-salient and non-race-salient versions of the case was the defendant's mention of his race in this exchange. ${ }^{55}$

In this study, Sommers and Ellsworth found that when race was not made salient, both White and Black mock jurors demonstrated racial bias. ${ }^{56}$ White mock jurors gave the Black defendant a significantly higher guilt rating than the White defendant, while Black jurors gave the White defendant a significantly higher guilt rating than the Black defendant. ${ }^{57}$ Both White and Black mock jurors were also more punitive in their sentence recommendations toward the other-race defendant when race was not made salient. ${ }^{58}$ White mock jurors rated the Black defendant's personality as significantly more aggressive and violent than the White defendant's, and Black mock jurors rated the White defendant's personality as significantly more aggressive and violent than the Black defendant's. ${ }^{59}$ When race was made salient, White mock jurors were more likely to treat the Black defendant the same as the White defendant. ${ }^{60}$ Black mock jurors, on the other hand, were still more lenient toward the Black defendant than the White defendant. ${ }^{61}$ Sommers and Ellsworth theorized that Black jurors may view the criminal justice system as inherently biased, and this belief might motivate them to demonstrate same-race leniency toward Black defendants to compensate for that bias. ${ }^{62}$

Sommers and Ellsworth's research is widely cited, but it is important to note that Sommers himself recognizes significant limitations in the work:

It remains the case, however, that too little is known regarding the psychological processes underlying the influence of a defendant's race. This gap in the literature prevents conclusions from being drawn regarding, for instance, whether prejudicial attitudes account for the influence of defendant race on White jurors, or whether simple awareness of societal stereotypes regarding race and crime is sufficient to impact judgments. ${ }^{63}$

One concern that judges and others may have is that making race salient might lead jurors to overcompensate. In other words, if judges or attorneys make race salient, then jurors might let guilty Black defendants go free and convict innocent White defendants. The research on race salience, however, 
suggests that making race salient simply reduces racial bias and results in White jurors treating similarly situated White and Black defendants the same; White mock jurors did not treat White defendants more harshly than similarly situated Black defendants.

\author{
The research on race salience... \\ suggests that making race salient \\ simply reduces racial bias and results \\ in White jurors treating similarly \\ situated White and Black defendants \\ the same.
}

\section{Awareness Alone Is Not Sufficient to Break the Prejudice Habit}

Raising awareness of the possibility of racial bias is a critical first step, but the existing research suggests educating people about implicit bias is not sufficient in and of itself to get them to break the prejudice habit. For example, for years it was thought that merely educating people about the value of cultural diversity and making them aware of the existence of prejudice would help reduce prejudice. ${ }^{64}$ While there is some evidence that voluntary enrollment in a class that focuses on the value of diversity can lead to bias reduction, ${ }^{65}$ it appears that mandatory enrollment in a diversity training program is not effective at reducing bias. ${ }^{66}$ This might be because some people resent being forced to expend time and effort on something they might view as political correctness training.

Similarly, it appears that simply telling people that they should try to avoid relying on stereotypes is not an effective way of permanently reducing bias. ${ }^{67}$ While telling people to suppress their stereotype-congruent responses may work in the short term, such interventions may lead to greater reliance on the stereotype when the person stops consciously trying to suppress the stereotype. For example, in one study, participants were shown a photograph of a skinhead and asked to write for five minutes on a day in the life of the person in the photograph. ${ }^{68}$ Half of the participants were told to try not to rely on stereotypes about skinheads when writing their narrative. ${ }^{69}$ The other half were not given a stereotype-suppression instruction. ${ }^{70}$ As might be expected, the narratives by the individuals told not to rely on stereotypes were less stereotypical than the narratives by the individuals in the control group who were given no such instruction. ${ }^{71}$ Sometime after this initial exercise, participants were shown a color photograph of another skinhead and asked to write about a day in this skinhead's life. ${ }^{72}$ This time, the narratives by the participants who were initially told to suppress stereotypes were more stereotypic than those by the control group. ${ }^{73}$

In a second experiment, which replicated the first part of the experiment described above, each participant was told after writing their narrative that they would meet the person in the photograph, and then the participant was taken to an adjacent room with eight empty chairs. ${ }^{74} \mathrm{~A}$ jacket and a backpack were on the first chair. ${ }^{75}$ The participant was told that the person in the photograph, 
the skinhead, must have gone to the restroom and would be right back. ${ }^{76}$ The participant was told to choose any seat. ${ }^{77}$ Interestingly, participants who had been given the stereotype-suppression instruction chose seats further away from the seat with the jacket and backpack, whereas participants in the control group who did not receive a stereotype-suppression instruction chose seats closer to the seat where the skinhead presumably had left his belongings. ${ }^{78}$ The researchers who conducted the study hypothesized that there is a rebound effect when individuals are told to suppress stereotypic thoughts. ${ }^{79}$ In other words, when people attempt to suppress unwanted thoughts, these thoughts will reappear later with even greater insistence than if they had never been suppressed. ${ }^{80}$ According to the authors of this study, this rebound effect happens "[a]s a consequence of the ironic monitoring process that occurs during suppression" because "unwanted constructs are continually stimulated or primed."

Other social science research also suggests that calling attention to race, either by asking people not to rely on race or asking them to rely on race, counterintuitively increases the tendency to rely on stereotypes. For example, B. Keith Payne tested whether actively highlighting race prior to the decision to shoot reduced or increased stereotype-congruent errors in the decision to shoot. ${ }^{82}$ Participants were told they would see pairs of pictures presented briefly-a face in the first picture and an object, either a gun or a hand tool, in the second picture-and they were to decide quickly whether the object in the second picture was a gun or a tool. ${ }^{83}$ Individuals in the control group were given no other instructions. ${ }^{84}$ Participants in the "Avoid Race" group were given the same instructions described above but were also told,

You have been randomly assigned to take the perspective of a completely unbiased person. Regardless of your personal views, we would like you to base your responses only on whether the second object looks more like a gun or tool. Try not to let the race of the face influence your decisions. ${ }^{85}$

Participants in the "Use Race" group were given the same instructions as the control group, but were also told,

You have been randomly assigned to the "racial profiling" condition. Regardless of your personal views, we would like you to play the role of someone engaged in racial profiling. That is, try to make correct classifications, but we would like you to use the race of the faces to help you identify the gun or tool in question. ${ }^{86}$

All participants misidentified tools as guns more often after seeing a Black face than after seeing a White face. ${ }^{87}$ They also misidentified guns as tools more often after seeing a White face than after seeing a Black face. ${ }^{88}$ Surprisingly, however, making race salient increased the tendency of individuals to stereotypically 
misidentify objects regardless of whether participants were told to avoid relying on race or to use race. ${ }^{89}$ Participants in both the "Avoid Race" and the "Use Race" conditions were more likely to misidentify harmless objects as guns when held by Blacks and misidentify guns as harmless objects when held by Whites than participants not given any instruction calling attention to race. ${ }^{90}$

What conclusions might we draw from these studies? A skeptic might conclude that making race salient helps reduce bias in some cases but exacerbates bias in other cases, so the best course of action is to do nothing. The research discussed above, however, suggests that salience reduces bias in complex settings where individuals have to make intricate judgments-like jurors deciding whether to find a defendant guilty or not guilty-but such salience may have the opposite effect when individuals have to make a quick decision, such as whether to shoot a suspect who appears to be armed or where to sit before a skinhead who has gone to the restroom returns to the room. In the courtroom setting, where the fact finder has time to consider different arguments and weigh the credibility of witnesses, making race salient is likely to be more beneficial than harmful. Indeed, research on implicit bias and judicial decision making by Jeffrey Rachlinski, one of the authors of Chapter 5, which addresses implicit bias in judicial decision making, lends support to this theory. ${ }^{91}$ In Rachlinski's study, White judges who showed a strong preference for Whites were able to mediate their pro-White preference and treat Black defendants fairly when they suspected that their decisions were being evaluated for racial bias. ${ }^{92}$

\section{Conclusion}

As discussed above, there are various ways to raise awareness about implicit bias. In the workplace setting, employers can give employees the opportunity to attend implicit bias workshops and lectures. In the courtroom, judges can educate jurors about implicit bias. Attorneys can also make bias salient during voir dire, in opening and closing statements, and through witness testimony.

Raising awareness about implicit bias is an important first step to reducing implicit bias, but it is only the first step. One must be motivated to break the prejudice habit and trained in ways to overcome implicit bias. The ensuing chapters will address various ways to motivate people to break the prejudice habit and overcome the implicit bias that affects us all.

\section{So You'd Like to Know More}

- Mahzarin R. Banaji \& Anthony G. Greenwald, Blindspot: Hidden Biases of Good People (2013)

- Jerry Kang et al., 59 UCLA Law Review 1124 (2012)

- Patricia G. Devine et al., 48 Journal of Experimental Social Psychology 1267 (2012)

- Carol Izumi, 34 Washington University Journal of LaW and Policy 71 (2010)

- $\quad$ Cynthia Lee, 5 UC Irvine Law Review 843 (2015) 


\section{About the Author}

Cynthia Lee is a law professor at The George Washington University Law School in Washington, D.C., where she teaches criminal law, criminal procedure, and professional responsibility. She is the author of Murder and the Reasonable Man (2003), a book that examines the ways that race, gender, and sexual orientation norms can influence verdicts in self-defense and provocation cases. She has also published several articles dealing with implicit racial bias, including "A New Approach to Voir Dire into Racial Bias," 5 U.C. Irvine L. Rev. 843 (2015) and "Making Race Salient: Trayvon Martin and Implicit Bias in a Not yet Post-Racial Society," 91 N.C. L. Rev. 1557 (2013). ${ }^{93}$

\section{ENDNOTES}

1. Gordon W. Allport, The Nature of Prejudice (1954).

2. See, e.g., Carmit T. Tadmor et al., Multicultural Experiences Reduce Intergroup Bias through Epistemic Unfreezing, 103 J. Personality \& Soc. Psychol. 750 (2012) (finding that exposure to multicultural experiences leads to a reduction in stereotype endorsement even for groups other than the comparative culture); Shawn O. Utsey et al., Prejudice and Racism, Year 2008-Still Going Strong: Research on Reducing Prejudice with Recommended Methodological Advances, 86 J. Counseling \& Development 339 (2008); Richard Crisp \& Sarah R. Beck, Reducing Intergroup Bias: The Moderating Role of Ingroup Identification, 8 Group Processes \& Intergroup Rel. 173 (2005).

3. Thomas F. Pettigrew \& Linda R. Tropp, A Meta-Analytic Test of Intergroup Contact Theory, 90 J. Personaltit \& Soc. Psychol. 751 (2006); Utsey et al., supra note 2.

4. Jerry Kang et al., Implicit Bias in the Courtroom, 59 UCLA L. Rev. 1124, 1130 (2012) (explaining how the IAT works).

5. Anthony G. Greenwald et al., Measuring Individual Differences in Implicit Cognition: The Implicit Association Test, 74 J. Personality \& Soc. Psychol. 1464, 1465-68 (1998).

6. Id. at $1465-70$.

7. Id. at 1467,1474 .

8. Becca R. Levy \& Mahzarin R. Banaji, Implicit Ageism, in Ageism: Stereotyping and Prejudice Against Older Persons 49, 54-55 (Todd D. Nelson ed., 2002).

9. Mahzarin R. Banaji \& Anthony G. Greenwald, Blindspot: Hidden Biases of Good People 69 (2013).

10. Id. at 47 .

11. Patricia G. Devine et al., Long-Term Reduction in Implicit Race Bias: A Prejudice HabitBreaking Intervention, 48 J. EXPERIMEnTAL Soc. Psychol. 1267, 1268 (2012) (finding that "breaking the habit" of prejudice or implicit bias "requires learning about the contexts that activate the bias and how to replace the biased responses with responses that reflect one's non-prejudiced goals").

12. Motivation to break the prejudice habit can be either internal or external. One is considered internally motivated to break the prejudice habit if one sincerely believes that it is morally wrong to discriminate against others. $I d$. at 1269 (noting that internal motivation to respond without prejudice "is primarily driven by personal values and the belief that prejudice is wrong"). One is considered externally motivated if the primary reason for conforming one's behavior to societal norms is so that one will not be seen as a bigot. $I d$. (noting that external motivation to respond without prejudice is "primarily driven by a desire to escape social sanctions").

13. The most important part of breaking the prejudice habit is training in bias reduction. While many debiasing interventions have been proposed, only a few appear to be effective at reducing implicit bias. In 2014, Calvin Lai and others conducted a comparative investigation of 17 debiasing interventions. Calvin K. Lai et al., Reducing Implicit Racial Preferences: I. A Comparative Investigation of 17 Interventions, 143 J. EXPERIMENTAL PSYCHOL. 1765 (2014). The most effective bias-reducing intervention was one in which participants were assigned to be on a dodge ball team in which all of their teammates were Black 
and all of the individuals on the opposing team were White. Id. at 1771 . Members of the all-White team engaged in unfair play. $I d$. At the end of the game, participants were asked to remember how their Black teammates helped them and their White opponents hurt them. Id. This intervention resulted in a reduction in implicit racial bias in favor of Whites and against Blacks. Id. The second most effective intervention was one in which participants read a story in the second-person narrative in which a White man assaults the participant and a Black man rescues the participant. $I d$. Participants took the race IAT both before and after reading the story. After reading the story, participants were told that the race IAT they would take would affirm that White is bad and Black is good and to keep the story they had just read in mind when taking the IAT. Id. This intervention successfully reduced participants' implicit racial preferences. Id. The third most successful intervention was one in which participants were shown six positive, well-known Black individual exemplars (one of whom was Bill Cosby, who was viewed positively at that time) and six negative, infamous White individual exemplars, such as Charles Manson. Id. Participants practiced taking an IAT that only paired Black faces with good things and White faces with bad things. Id. This intervention was also effective at reducing implicit preferences. Id. A similar experiment by Nilanjana Dasgupta and Anthony Greenwald found that exposure to pictures of famous admired Black individuals and infamous disliked White individuals resulted in a reduction in automatic implicit racial bias in favor of Whites. Nilanjana Dasgupta \& Anthony G. Greenwald, On the Malleability of Automatic Attitudes: Combating Automatic Prejudice with Images of Admired and Disliked Individuals, 81 J. Personality \& Soc. Psychol. 800 (2001).

14. Masua Sagiv, Cultural Bias in Judicial Decision Making, 35 B.C. J.L. \& Soc. Just. 229, 254 n.114 (2015) ("Research in the field of law and psychology is divided as to the significance that an individual's awareness of her own bias has in reducing or diminishing it."); Linda Babcock et al., Creating Convergence: Debiasing Biased Litigants, 22 Law \& Soc. Inquiry 913, 916 (1997) (arguing that merely making someone aware of a bias won't make him or her less biased, but having people think about counterarguments or weaknesses in their position helps reduce self-serving biases).

15. As Carol Izumi notes, "Awareness of bias is critical for mental decontamination success." Carol Izumi, Implicit Bias and the Illusion of Mediator Neutrality, 34 WASH. U. J.L. \& POL'Y 71, 141 (2010) (citing Laurie A. Rudman et al., "Unlearning" Automatic Biases: The Malleability of Implicit Prejudice and Stereotypes, 81 J. Personality \& Soc. Psychol. 856 (2001)).

16. Jessica Guynn, Google's 'Bias-Busting' Workshops Target Hidden Prejudices, USA Today (May 12, 2015), http://www.usatoday.com/story/tech/2015/05/12/google-unconscious-bias -diversity/27055485/; Farhad Manjoo, Exposing Hidden Bias at Google, N.Y. Times, Sept. 24, 2014, http://www.nytimes.com/2014/09/25/technology/exposing-hidden-biases -at-google-to-improve-diversity.html?_r=0.

17. Jennifer Nasser, Manhire Presents Bias Workshop to Texas A\&M Law, Tex. A\&M Univ. ScH. OF LAW (Oct. 8, 2015), https://law.tamu.edu/media/news-media-resources/story /manhire-presents-bias-workshop-to-tamu-law (discussing workshop on overcoming implicit bias for faculty and staff at Texas A\&M Law School).

18. Lorie Fridell, Producing Bias-Free Policing: A Science Based Approach (2016); Lorie Fridell, Fair and Impartial Policing, http://www.fairimpartialpolicing.com/; Tami Abdollah, Police Agencies Line up to Learn about Unconscious Bias, CNS News (Mar. 9, 2015), http:// www.cnsnews.com/news/article/police-agencies-line-learn-about-unconscious-bias. Sarah Green Carmichael, Training Police Departments to Be Less Biased, Harv. Bus. Rev. (Mar. 6, 2015), https://hbr.org/2015/03/training-police-departments-to-be-less-biased; Rio Fernandes, How Bias Training Works in One Campus Police Department, Chron. Higher Educ., May 16, 2016, http://chronicle.com/article/How-Bias-Training-Works-in -One/236482; Matt Zapotosky, Can Police Police Their Biases? Training Is Underway, WAsh. Post MAG., Apr. 3, 2016, at 23 (describing some of the videos that were shown in a recent training of Virginia State Troopers near Richmond, Virginia); Lisa Grace Lednicer, What Police Are Learning, WAsh. Post MAG., Feb. 22, 2015, at 17 (describing the fair and impartial policing training of police officers led by Lorie Fridell). 
19. Jessica Guynn, Diversity Gets Googled, USA TodaY, May 7, 2015, at B2.

20. Emily Badger, Airbnb Details Plans to Enrich Nondiscrimination Policy, Wash. Post, Sept. 9, 2016, at A17.

21. Eric Yoder, Justice Dept. Employees to Undergo Training on Implicit Bias, Wash. Post, June 29, 2016, at A17; see also Julia Edwards, Justice Dept. Mandates "Implicit Bias" Training for Agents, Lawyers, ReuTERs.COM, June 27, 2016, http://www.reuters.com/article/us -usa-justice-bias-exclusive-idUSKCNOZD251.

22. Judge Bennett is the author of Chapter 4, Manifestations of Implicit Bias in the Courts, which examines several ways in which implicit bias affects lawyers, jurors, and judges.

23. Anna Roberts, (Re)forming the Jury: Detection and Disinfection of Implicit Juror Bias, 44 Conn. L. Rev. 827, 859 (2012), also available at http://wispd.org/attachments/article /101/ImplicitBiasJuryInstruction.pdf. Jury orientation videos can also inform prospective jurors about implicit bias. $I d$. (proposing that jury orientation videos educate prospective jurors about implicit bias). I was called for jury duty in May 2016 and was pleased to see that D.C. Superior Court had adopted a new jury orientation video, narrated by Andrew Ferguson, Professor of Law at the University of District of Columbia David A. Clarke School of Law and author of Why Jury Duty MatTers: A Citizen's Guide to Constitutional Action (2013). The new jury orientation video focuses on the role of the juror in upholding our democratic values, and while it does not address implicit bias per se, it does talk about bias in general and the need to guard against bias. See We the People: A Call to Duty (2014), available at http://www.dccourts.gov/juryvideo.

24. Cynthia Lee, A New Approach to Voir Dire into Racial Bias, 5 UC Irvine L. Rev. 843 (2015).

25. Like many others who write about race, I purposely capitalize the "B" in "Black" and the "W" in "White" to highlight the fact that Blacks and Whites are commonly perceived in the United States as members of clearly defined racial groups.

26. James McComas \& Cynthia Stout, Combating the Effects of Racial Stereotyping in Criminal Cases, The Champion 22-23 (Aug. 1999).

27. Id.

28. Cynthia Kwei Yung Lee, Race and Self-Defense: Toward a Normative Conception of Reasonableness, 81 Minn. L. Rev. 367, 482 (1996) (suggesting a model limiting instruction on the impropriety of relying on racial stereotypes); see also Cynthia Lee, Murder and the Reasonable Man: Passion and Fear in the Criminal Courtroom 224-25 (2003) (proposing a race-switching jury instruction in cases involving a risk that racial stereotyping will influence the jury's determination of reasonableness).

29. McComas \& Stout, supra note 26.

30. Cynthia Lee, The Gay Panic Defense, 42 UC Davis L. Rev. 471, 564-65 (2008); Cynthia Lee \& Peter Kwan, The Trans Panic Defense: Masculinity, Heteronormativity, and the Murder of Transgender Women, 66 Hastings L.J. 77, 105 (2014).

31. Patricia G. Devine, Stereotypes and Prejudice: Their Automatic and Controlled Components, 56 J. Personaltiy \& Soc. Psychol. 5, 5-6, 15 (1989) (suggesting five strategies to reduce bias, including counter-stereotypic imaging, obtaining specific information about individuals in a group, taking the perspective of the person in the stereotyped group, and increased opportunities for contact with outgroup members). See also Molly Carnes et al., The Effect of an Intervention to Break the Gender Bias Habit for Faculty at One Institution: A Cluster Randomized, Controlled Trial, 90 ACADEMIC MED. 221 (2015) (finding that gender bias was reduced when individuals were given specific behavioral strategies to practice, such as replacing a gender stereotype with accurate information, positive counter-stereotype imaging, imagining in detail what it is like to be a person in a stereotyped group, and meeting with counter-stereotypic exemplars, such as senior women faculty).

32. Anna Roberts reports that the "National Center for State Courts attempted the first empirical testing of jury instructions like [Judge Bennett's], and found no significant influence of the instructions on jurors' verdict preferences." Anna Roberts, Jury Failures and Reform Post-Ferguson (work-in-progress presented at the 2016 SEALS Annual Meeting, Amelia Island, Florida, on Aug. 4, 2016) (manuscript on file with author), citing Jennifer K. Elek \& Paula Hannaford-Agor, Can Explicit Instructions Reduce Expressions 
of Implicit Bias? New Questions Following a Test of a Specialized Jury Instruction *8, 14 (National Center for State Courts, Apr. 2014), archived at http://perma.cc/ZZD4-XD73.

33. Elek \& Hannaford-Agor, supra note 32 (finding "no significant effects . . . on judgments of guilt, confidence, strength of the prosecution's evidence, or sentence length" when testing a specialized implicit-bias jury instruction "[b]ased loosely on [the] jury instruction developed and used by Judge Mark Bennett").

34. Samuel R. Sommers \& Phoebe C. Ellsworth, White Juror Bias: An Investigation of Prejudice against Black Defendants in the American Courtroom, 7 Psychol. Puв. Pol'y \& L. 201, 216 (2001).

35. Id.

36. Id.

37. Id. at 214-16.

38. Id.

39. Id.

40. Id.

41. Id.

42. Id. at 217 .

43. Id.

44. Id. at 218.

45. Id. at 219 .

46. Id.

47. Id. at 220 .

48. Id.

49. Samuel R. Sommers \& Phoebe C. Ellsworth, Race in the Courtroom: Perceptions of Guilt and Dispositioned Attributions, 26 Personality \& Soc. Psychol. Bull. 1367, 1372-73 (2000). Of the 211 participants, 156 identified themselves as White and 55 identified themselves as Black.

50. Id.

51. Id. at 1373 .

52. Id.

53. Id.

54. Id.

55. Id. Because the case raised issues of gender as well as race, Sommers and Ellsworth included gender of the mock juror as an independent variable in their analysis and found no significant main effects. Id. at 1377.

56. Id. at 1374 .

57. Id.

58. Id.

59. Id. at 1375 .

60. Id. Black mock jurors, on the other hand, were more lenient toward the Black defendant than the White defendant. Id. Sommers and Ellsworth theorized that Black jurors may view the criminal justice system as inherently biased, and this belief might motivate them to demonstrate same-race leniency toward Black defendants to compensate for that bias. Id. at 1376 .

61. Id.

62. Id. At least one other research team has found results similar to Sommers. See, e.g., Ellen S. Cohn et al., Reducing White Juror Bias: The Role of Race Salience and Racial Attitudes, 39 J. Applied Soc. Psychol. 1953 (2009); Donald O. Bucolo \& Ellen S. Cohn, Playing the Race Card: Making Race Salient in Defence Opening and Closing Statements, 15 LEGAL \& Criminological Psychol. 293 (2010).

63. Samuel Sommers, Race and the Decision Making of Juries, 12 Legal \& Criminological Psychol. 171, 174 (2007).

64. Clark McCauley et al., Diversity Workshops on Campus: A Survey of Current Practice at US Colleges and Universities, 34 College Student J. 100 (2000) (finding that 81 percent of U.S. colleges and universities have held diversity workshops). 
65. Lorie A. Rudman et al., "Unlearning" Automatic Biases: The Malleability of Implicit Prejudice and Stereotypes, 81 J. Personality \& Soc. Psychol. 856 (2001) (finding that students who voluntarily enrolled in a prejudice and conflict seminar taught by a Black professor showed reduced implicit and explicit anti-Black bias at the end of the semester compared to students who were not enrolled in the seminar).

66. Peter Bregman, Diversity Training Doesn't Work, Harv. Bus. Rev., https://hbr.org/2012/03 /diversity-training-doesnt-work (Mar. 12, 2012), citing Frank Dobbin et al., Diversity Management in Corporate America, 6 CONTEXTs 21 (2007); Suzanne Lucas, Why You Should Stop Attending Diversity Training, CBS News, http://www.cbsnews.com/news/why-you -should-stop-attending-diversity-training/ (May 2, 2012); Shankar Vedantam, Most Diversity Training Ineffective, Study Finds, WASH. Post, Jan. 20, 2008, http://www.wash ingtonpost.com/wp-dyn/content/article/2008/01/19/AR2008011901899.html.

67. Linda Babcock et al., Creating Convergence: Debiasing Litigants, 22 LAW \& Soc. INQUiRY 813, 916 (1997) ("many researchers have tried, albeit unsuccessfully, to mitigate various biases by informing subjects about them-for example, by telling subjects about the hindsight bias and its effects").

68. C. Neil Macrae et al., Out of Mind but Back in Sight: Stereotypes on the Rebound, 67 J. Personality \& Soc. Psychol. 808, 810 (1994).

69. Id.

70. Id.

71. Id. at 811

72. Id. at 810 .

73. Id. at 811 .

74. Id.

75. Id.

76. Id.

77. Id.

78. Id. at 812 .

79. Id. at $813-14$.

80. Id. at 814 (concluding that "[o]ut of sight . . does not necessarily mean out of mind, at least where unwanted thoughts are concerned.").

81. Id. at 812 .

82. B. Keith Payne, Alan J. Lambert \& Larry L. Jacoby, Best Laid Plans: Effects of Goals on Accessibility Bias and Cognitive Control in Race-Based Misperceptions of Weapons, $38 \mathrm{~J}$. Experimental Soc. Psychol. 384 (2002).

83. Id. at 388 .

84. Id.

85. Id.

86. Id.

87. Id. at 389.

88. Id.

89. Id. at 390-91.

90. Id.

91. Jeffrey J. Rachlinski et al., Does Unconscious Racial Bias Affect Trial Judges?, 84 Notre Dame L. Rev. 1195 (2009).

92. Id.

93. Professor Lee thanks Christina Stevens Carbone, Phyllis Pickett, and Jeffrey Rachlinski for enormously helpful comments on this chapter. She also thanks Andrew Hyun, Christine Kulumani, and Madeline DiLascia-Azia for helpful research assistance support on this chapter and Prerna Balasundaram for administrative assistance. Finally, she thanks Sarah Redfield for inviting her to be a contributing author for this book. 